\title{
REVIEW
}

Ann R Coll Surg Engl 2006; 88: 261-264

doi $10.1308 / 003588406 \times 106315$

\section{Consent in surgery}

\section{ROBERT WHEELER}

\section{Wessex Regional Centre for Paediatric Surgery, Southampton General Hospital, Southampton, UK} ABSTRACT

A review of consent for surgery is timely. As the length of surgeons' training diminishes, despite the increasing interest in the content of the surgical curriculum, the law governing the process of gaining consent has been given scant attention. The advent of non-medically qualified surgical practitioners raises questions about the breadth of knowledge that is required to ensure that valid consent is obtained. Consent is as fundamental as any other basic principle on which surgical practice relies, and its use in patient care is a clinical skill.

The 'traditional' approach to consent contained some negative elements. A doctor who was incapable of performing the proposed operation often obtained consent. In a genuine attempt to protect patients from anxiety, the rare-but-grave potential complications were sometimes not discussed. There was uncertainty about what should properly be disclosed, compounded by conflicting messages from the courts. The consent was sometimes taken from people who were ineligible to provide it.

These could be viewed as aberrations, and some persist. Having clarified the necessity for consent, this review concludes that it should be obtained by the operating surgeon. The threshold for interventions that need formal consent is discussed, together with the legal tests for capacity. In considering the recent law, it becomes clear that any potential complication that the reasonable patient would need to take into consideration before deciding to give their consent is one that should be disclosed.

\section{KEYWORDS}

\section{Consent - Disclosure - Capacity - Formalities}

\section{CORRESPONDENCE TO}

Mr Robert Wheeler MB LLB(Hons) FRCS FRCPCH, Consultant Paediatric \& Neonatal Surgeon, Wessex Regional Centre for Paediatric

Surgery, Southampton General Hospital, Tremona Road, Southampton S016 6YD, UK

E: robert.wheeler@suht.swest.nhs.uk

\section{Why is consent necessary?}

Consent protects the doctor from the accusation of an unwanted touch. Whilst the jostling on the crowded train or the melee in the supermarket at Christmas inevitably results in uninvited and potentially unwelcome touches from strangers, society dismisses these as inevitable irritants of modern life. However, the strong principle that a stranger will not touch us without our permission is all pervasive, and is an important manifestation of our individual autonomy.

The requirement for consent has now explicitly been extended to the disposal of human tissue and the management of personal data. Although these extensions are not a central issue for surgeons, they clearly have great implications during the consent process, because this gives the hospital the opportunity to ensure that the patient's permission to use resected tissue for diagnosis, and tissue remnants for research, teaching and quality control can be demonstrated. Equally, the attitude of the patient to photography, and the final use of resultant images, can be recorded.

\section{The consequences of failing to gain consent}

These are, to an extent, proportionate to the affront caused. Most patients will automatically accept the first touch, because that is the welcoming handshake. Many patients would silently object to their abdomen being pummelled unless they were politely asked their permission, but most would dismiss it merely as rudeness on the doctor's behalf. However, an adverse outcome, combined with invalid consent, is increasingly likely to lead to a successful claim in clinical negligence. ${ }^{1}$

\section{Which interventions require consent?}

It is possible to understand the view that by merely attending a clinic, patients are already providing consent. Furthermore, if they roll up their sleeve and remain motionless as the venesection needle is approaching, surely their consent can be deduced from their behaviour?

Although common sense suggests that this is true, English law is unwilling to recognise this as valid consent. 
Where a reasonable person, observing the situation, would conclude that the patient had agreed to the intervention, the doctor will have a defence based upon implied consent. This is a fiction, since there is no valid consent. However, the patient's lack of objection at the time of the procedure means that he will not subsequently be permitted to rely on the fact that he did not actually consent.

It can be seen that although this is a pragmatic approach to routine and minimal-risk interventions, the absence of consent makes it risky for the clinician. Implied consent is often invoked to justify the activities of medical students. If a reasonable person observes a man or woman going into a teaching hospital, they would not necessarily deduce that they had agreed to repeated examinations by medical students. However, if there were prominent intelligible signs displayed, in a variety of languages, which explained this likelihood to anyone entering the hospital, and gave the patient the opportunity to 'opt out' of student examinations, the reasonable observer would probably suggest that the patient's subsequent co-operation with student teaching implied consent.

The law does not directly prescribe a threshold above which a formal conversation between doctor and patient concerning consent should occur. As a general rule, the more controversial or invasive an intervention becomes, the greater the need to ensure that the patient has given their consent. For example, the discussion before consent for a venesection for liver function tests is unlikely to enumerate the various elements of the laboratory test, e.g. enzymes, proteins, etc. In normal circumstances, such detail would be seen as inappropriate. However, if performing an identical procedure for an HIV test, the alternatives and consequences must be discussed in depth.

Equally, the normal courtesies before an abdominal examination would not suffice for a vaginal examination; and both may need some further words of explanation if they include an element of training.

\section{The recording of consent}

In the place of a prescribed threshold, the law relies upon a comparison with the practise of a reasonable doctor ${ }^{2}$ to determine the form of consent provided for any particular intervention.

There is no requirement in common law for written consent. There are some statutes that make it mandatory for specified procedures, such as forms of fertility treatment, ${ }^{3}$ but the value of the signed consent form is that it provides some evidence of a contract between the patient and the doctor. If only for the purposes of defending claims, the state and, therefore, hospitals, make signed consent mandatory.

This can be both misleading and problematic.

It is misleading because it promotes the myth that a signed form is synonymous with valid consent. Of course, in the vast majority of cases, one leads naturally from the other. However, it would be perfectly possible for a patient to sign a form without having the slightest idea what surgery was being proposed, and simply signed to conform with the doctor's bidding. Should the 'consent' process subsequently be scrutinised, it will be very obvious that whilst the patient signed the form correctly, they had no understanding of the procedure or any matters pertaining to it; the consent is invalid. Consent expressed 'in form only' is no consent at all. ${ }^{4}$

It is problematic because it begs the question of the threshold for 'intermediate' procedures; do we need written consent for lumbar puncture, chest drains, etc.? Can such procedures be considered as merely an integral part of the treatment plan, and thus covered by one all-encompassing consent at the beginning of the treatment programme?5

This has lead to fragmentary local practice and confusion, but no 'legal' clarification has emerged, or is likely. Surgeons should rely on a combination of the reasonable practitioner and commonsense, because these are clinical decisions, like any other. If in all the circumstances, either the patient or the procedure seems to merit written consent, then it should be obtained. However, for many intermediate procedures, a simple record in the case notes of the discussion and the patient's agreement suffices, and would currently represent practice well within the reasonable standard of care.

If in doubt whether a particular intervention requires written consent, reference should be made to local practice, and the local Clinical Ethics Committee ${ }^{6}$ will be able to provide assistance.

Guidance may also be available, produced as protocols or guidelines, either locally, by speciality organisations and Colleges, or by organisations such as the NPSA or NICE.

Although this guidance has no mandatory status, it may be persuasive to courts, and if a surgeon chooses to practice at variance with such guidance, the reasons behind the variance should be capable of withstanding comparison with their peers, and be based upon logic. ${ }^{7}$

\section{Does the patient have the capacity to consent?}

To determine whether an adult patient has the ability to understand what is involved, the courts have developed a three-stage test (Table 1). ${ }^{8}$

\section{Table 1 The three-stage test ${ }^{8}$}

The patient must be able to:

- Comprehend and retain the relevant information

- Believe it

- Weigh it in the balance so as to arrive at a choice 


\section{Table 2 Children's capacity to consent ${ }^{9}$}

A child may demonstrate capacity by being able to:

- Understand in simple language what the medical treatment is, its purpose and nature and why it is being proposed

- Understand its principal benefits, risks and alternatives

- Understand in broad terms what will be the consequences of not receiving the proposed treatment

- Retain the information for long enough to make an effective decision

- Make a free choice

On the basis of this test, a clinical decision is taken as to whether the patient will be able to give valid consent. There is no requirement for a patient to make a 'mature' or 'wise' choice; neither should their decision necessarily be 'rational', providing that their irrationality does not reflect a mental disability that would cause them to fail one of the three stages.

A child of 16 years is presumed to have the capacity to consent, although a parent or the local authority may also give consent under some circumstances up to the age of 18 years. There is no presumption that children below 16 years have capacity, but it may be demonstrated by a child of any age (Table 2). ${ }^{9}$ This is clearly a comprehensive test of capacity. This is to be expected, as it would be inappropriate to allow children to agree to interventions if there was a risk that they were not fully aware of what they are agreeing to. Nevertheless, it is clear that, on a daily basis, many adults who give their consent unchallenged would fail this test.

It should be noted that a child's capacity can only be determined in the context of the proposed treatment. A child who has the capacity to consent independently for a peripheral cannula may have insufficient capacity to consent for a long-term central venous catheter (CVC). Equally, a child's experience, as well as age, will have a profound effect on capacity. A 12-year-old who has spent many months on an oncology ward is much more likely to have the capacity to consent to CVC re-insertion than the 14-year-old whose diagnosis was only made 2 days previously.

\section{What should be disclosed, and by whom?}

There is abundant published guidance ${ }^{10}$ on the information that should be provided when seeking consent (Table 3). It can immediately be seen that this presents a relatively exhaustive list of potential topics for discussion. It seems likely that a medical training would place the surgeon in an ideal position to answer the more diverse questions.

Someone who is capable of performing the surgery should obtain consent. It is unlikely that any member of the surgical team who has not reached this stage will have the experience to address the many possible ramifications that may emerge during the consent discussion. There are no legal rules stipulating this as a requirement. However, there are indications from recent judgements that the judiciary expect this standard of care. ${ }^{11}$

As surgeons, we continue to have a keen interest in what should be disclosed, particularly in terms of the adverse consequences of surgery. There are three main options. ${ }^{12}$

\section{Option 1}

All the information that the index patient wishes to know should be passed on. Since the patient in front of you has set the standard of provision, this is a subjective standard. This option corresponds with the North American doctrine of 'informed consent'. Although laudable from the point of view of patients' rights, the standard causes difficulty. Should it be expressed as what the patient wishes to know or what the patient would wish to know (if only he knew)? The former is hard enough to satisfy. The latter verges on the impossible. ${ }^{13}$

\section{Option 2}

The surgeon should inform the patient of what other surgeons in this speciality think it is appropriate for the patient to know. This is the professional standard, based upon the belief that the surgeon is best placed to determine what information is necessary to facilitate consent decisions. Accepting the obvious objections to paternalism,

\section{Table 3 Information to be provided when seeking consent ${ }^{10}$}

- The purpose and details of the investigation or treatment

- Details and uncertainties of the diagnosis

- Options for treatment and the likely prognosis, including the option not to treat

- Explanation of the likely benefits and probabilities of success for each option

- Known possible side effects

- The name of the doctor who will have overall responsibility

- A reminder that the patient can change his or her mind at any time 
this approach also has the danger of concentrating only upon the medical facets of the decision, potentially ignoring the 'human' and personal factors which may weigh heavily with the patient, but which are not shared by his surgeon. It also begs the question of whether there is a significant uniformity of surgical opinion to make it likely that coherent guidance on a standard of disclosure will be forthcoming?

\section{Option 3}

The surgeon should pass on that information which any reasonable patient would wish to know before giving consent. This has the advantage of using an objective standard beloved by lawyers, the 'reasonable person'. The surgeon would have to consider the position from the 'reasonable person's' point of view, and impart the information to the patient accordingly. There is obviously a danger that the particular patient's circumstances will not be considered during this 'virtual reality' exercise. Crucially, the adoption of the objective standard would allow the courts to determine whether the standard of disclosure had been achieved, effectively excluding the need to hear evidence from doctors relating to the professional standard.

Perhaps surprisingly, option 2 best represents the current English law.

The Bolam judgement ${ }^{14}$ established that a doctor's standard of care should be judged by comparison with the views of a responsible body of doctors. Thirty years later, in Sidaway (another 'consent case'), ${ }^{15}$ the House of Lords were given their first opportunity to explore the ideological clash between a traditional reluctance to challenge professionals, and an increasing determination to make doctors accountable for their actions. In a split decision, their Lordships came to diverse conclusions, and at least three very different threads of opinion and reasoning emerged from Sidaway.

However, the prevailing view is that it confirmed that the doctor's duty to exercise reasonable skill and care included a duty to inform patients during the process of gaining consent. Furthermore, the standard of information provision should be judged according to the Bolam criteria.

Nevertheless, the dissonance within the judgement continues to cause considerable uncertainty, fuelled by mounting political pressure on perceived medical paternalism. It is, therefore, all the more surprising, (given the increasing pre-occupation with personal autonomy), that 2 years later, another judgement selected the Sidaway thread of opinion most consistent with the traditional Bolam approach as the correct approach. ${ }^{16}$ In the US, despite the publicity surrounding the doctrine of informed consent, most States still rely upon the professional standard. ${ }^{17}$ In Canada ${ }^{18}$ and Australia,,${ }^{19}$ option 3 (the reasonable patient) has been firmly adopted.

\section{Significant or material risks?}

Notwithstanding Sidaway, recent cases have shown that English law is moving towards the 'reasonable patient' standard. During disclosure for consent, a doctor has a duty to inform a patient of any material facts relating to risks and alternatives. In a recent judgement, Lord Woolf concluded that: ${ }^{20}$

If there is a significant risk which would affect the judgement of a reasonable patient, then in the normal course it is the responsibility of a doctor to inform the patient of that significant risk, if the information is needed so that the patient can determine ... what course he or she should adopt.

This clearly begs the question of what is 'significant'. Whether that is a matter of clinical judgement (and Bolam), or a matter for the courts (unfettered by the 'professional' standard), still remains to be seen.

\section{Acknowledgement}

The author is a paediatric surgeon with a particular interest in paediatric oncology. He has an established practice in medical law, and has published extensively in the fields of consent, clinical negligence and child law. He is chairman of the Clinical Ethics Committee of the British Association of Paediatric Surgeons. This article reflects his clinical and legal experience in these areas of law.

\section{Bibliography}

1. Chester v Afshar [2004] UKHL 41.

2. Bolam v Friern HMC [1957] 1 WLR 582.

3. Human Fertilisation and Embryology Act 1990.

4. Chatterton v Gerson [1981] 1 All ER 257, 265 per Bristow J.

5. Montgomery J. Health Care Law. Oxford: OUP, 2003; 236.

6. <www.ethics-network.org.uk>

7. Bolitho v City \& Hackney HA [1997] 4 All ER 771.

8. Re C (Adult: Refusal of medical treatment) [1994] 1 All ER 819, 824 per Thorpe J.

9. British Medical Association. Consent Tool Kit. London: BMA, 2001

10. General Medical Council. Seeking patients' consent: the ethical considerations. London, GMC, 1998.

11. Chester v Afshar [2004] UKHL 41, per Ld Hoffman.

12. Grubb A. Principles of Medical Law 3. Oxford: OUP, 2004; 116-3, 151.

13. Grubb A. Principles of Medical Law 3. Oxford: OUP, 2004; 118.

14. Bolam v Friern HMC [1957] 1 WLR 582.

15. Sidaway v Bethlem royal Hospital Governors [1985] 1 All ER 643.

16. Gold v Haringey HA [1988] QB 481.

17. Rosenblatt $L$ et al. Law and the American Health Care System. New York: Foundation Press, 1997; 901

18. Reibl v Hughes [1980] 114 DLR (3d) 1, @ 11 per Laskin CJ.

19. Rogers v Whittaker [1992] 67 ALJR 47.

20. Pearce v United Bristol Healthcare NHS Trust [1998] 48BMLR 118 (CA). 